Nuraini A. • Y. Rochayat · D.Widayat

\title{
Rekayasa source - sink dengan pemberian zat pengatur tumbuh untuk meningkatkan produksi benih kentang di dataran medium desa Margawati kabupaten Garut
}

\section{Source - sink engineering by the substance of growth regulator application to increase of seed potatoes production on medium land, Margawati village district of Garut}

\author{
Diterima : 15 Februari 2016/Disetujui : 1 Maret 2016 / Dipublikasikan : Maret 2016 \\ CDepartment of Crop Science, Padjadjaran University
}

\begin{abstract}
Production of potatoes is influenced by the availability of seed. A lack of supply or availability of seed potato will affect the production of potatoes. This study was conducted to test the quality of the potato tuber G2 generated by the system Nutrient Film Technique in the field. The experiments were performed on a medium in Garut plains with altitude of about $700 \mathrm{~m}$ above sea level to produce seed potatoes G3 by treatment with cytokines application of 0 , 5,10 and $15 \mathrm{ml} / \mathrm{L}$ and paclobutrazol $0,15,30$ and $45 \mathrm{ml} / \mathrm{L}$. Experiments using a factorial randomized block design pattern. The first factor wasthe concentrations of cytokines: $0,5,10$ and $15 \mathrm{ml} / \mathrm{L}$, and the second factor was concentrations of paclobutrazol: 0, 15,30 and $45 \mathrm{ml} / \mathrm{L}$. The experimental results showed that there was no interaction effect of the concentration of cytokinin with paklobutrazol concentration on the quantity and quality of seed potatoes G3. The concentration of cytokines that best effected to the quantity and quality of seed potato G3 was $5 \mathrm{ml} / \mathrm{L}$, whereas the concentration of the most well paklobutazol was $15 \mathrm{ml} / \mathrm{L}$.
\end{abstract}

Keywords: Seed · Potatoes · Cytokines .

Paklobutrazol $\cdot$ Medium land

Sari Produksi kentang dipengaruhi oleh ketersediaan benihnya. Kurangnya pasokan atau ketersediaan benih kentang akan berpengaruh pada produksi kentang. Penelitian ini dilakukan untuk menguji kualitas ubi kentang G2 yang

\footnotetext{
Dikomunikasikan oleh Agus Wahyudin

Nuraini, A. · Y. Rochayat · D. Widayat

Departemen Budidaya PertanianFakultas Pertanian

Universitas Padjadjaran

Korespondensi : nuraini_yunandar@yahoo.com
}

dihasilkan dengan sistem Nutrient Film Technique (NFT) di lapangan. Percobaan dilakukan pada dataran medium di Garut dengan ketinggian tempat sekitar $700 \mathrm{~m}$ di atas permukaan laut untuk menghasilkan benih kentang G3 dengan perlakuan aplikasi sitokinin 0, 5, 10 dan $15 \mathrm{ml} / \mathrm{L}$ dan paklobutrazol 0, 15, 30 dan $45 \mathrm{ml} / \mathrm{L}$. Percobaan menggunakan Rancangan Acak Kelompok Pola Faktorial. Faktor pertama adalah konsentrasi sitokinin yaitu : 0, 5, 10 dan $15 \mathrm{ml} / \mathrm{L}$, dan faktor kedua adalah konsentrasi paklobutrazol yaitu : 0, 15, 30 dan $45 \mathrm{ml} / \mathrm{L}$. Hasil percobaan menunjukkan bahwa tidak terjadi pengaruh interaksi konsentrasi sitokinin dengan konsentrasi paklobutrazol terhadap kuantitas dan kualitas benih kentang G3. Konsentrasi sitokinin yang paling baik dalam menghasilkan kuantitas dan kualitas benih kentang G3 adalah $5 \mathrm{ml} / \mathrm{L}$, sedangkan konsentrasi paklobutazol yang paling baik adalah $15 \mathrm{ml} / \mathrm{L}$.

Kata kunci: Benih · Kentang · Sitokinin .

Paklobutrazol · Dataran medium

\section{Pendahuluan}

Kentang (Solanum tuberosum L.) merupakan salah satu bahan pangan utama yang diminati dunia setelah gandum dan beras (FAOSTAT, 2006). Kentang merupakan bahan pangan yang menunjang program diversifikasi pangan karena kandungan gizinya. Kandungan gizi kentang antara lain karbohidrat, vitamin dan mineral dengan komposisi utama ubi kentang terdiri atas $80 \%$ air, $18 \%$ pati dan $2 \%$ protein, serta mineral yang terdiri atas kalsium, fosfor, zat besi, magnesium, kalium, natrium, klorin, sulfur, tembaga, mangan dan kobalt (Pitojo, 2004). 
Produksi kentang di Indonesia mengalami fluktuasi dari tahun ke tahunnya. Tahun 2011 produksi kentang di Indonesia mencapai 955.448 ton dari luas panen 59.882 ha dengan produktivitas 15,96 ton/ha. Tahun 2012 produksi kentang di Indonesia mencapai 1.094.240 ton dari luas panen 65.989 ha dengan produktivitas 16,58 ton/ha. Tahun 2013 produksi kentang di Indonesia mencapai 1.124.282 ton dari luas panen 70.187 ha dengan produktivitas 16,02 ton/ha. Data tersebut menunjukkan bahwa pada tahun 2013 terjadi penurunan produktivitas sekitar 0,56 ton/ha (Badan Pusat Statistik, 2014).

Rendahnya produktivitas kentang dapat dipengaruhi banyak hal. Menurut Wattimena (2000), rendahnya produktivitas disebabkan oleh (1) rendahnya kualitas dan kuantitas benih kentang, (2) kurangnya benih kentang bermutu, tepat waktu, dan tepat umur fisiologis, (3) faktor topografi, dimana daerah dengan ketinggian tempat dan temperatur yang sesuai untuk pertanaman kentang di Indonesia sangat terbatas, (4) pengendalian hama dan penyakit tanaman kentang yang masih kurang, (5) kurang tersedianya kultivar kentang yang sesuai untuk kebutuhan pasar dan lingkungan tumbuh.

Peningkatan produksi benih kentang baik kuantitas maupun kualitas dapat dilakukan dengan rekayasa source-sink tanaman kentang yaitu dengan cara pemberian zat pengatur tumbuh (ZPT), diantaranya sitokinin dan paklobutrazol. Sitokinin merupakan ZPT yang berperan dalam merangsang pertumbuhan tanaman. Fungsi utama sitokinin adalah memacu pembelahan sel dan memacu pembesaran sel. Bradshaw, et al. (2009) menyatakan bahwa kadar sitokinin naik dengan tajam sesaat sebelum inisiasi ubi. Kadar sitokinin tersebut tetap tinggi sampai ubi mendekati masak, kemudian turun. Sitokinin memacu pemben-tukan ubi dengan jalan menghambat aktivitas hidrolisis pati dan sebaliknya merangsang aktivitas sintesis pati.

Peningkatan sitokinin dalam tanaman dapat meningkatkan jumlah stolon tanaman kentang. Stolon yang berbuku akan bercabang pada setiap bukunya sehingga dapat meningkatkan jumlah bagian terminal stolon. Terminal stolon merupakan tempat terbentuknya ubi kentang, namun demikian semakin banyak jumlah terminal stolon tidak menentukan jumlah ubi. Hal ini disebabkan adanya aktivitas kerja hormon giberelin di dalam tanaman. Terminal stolon akan terus tumbuh memanjang dan membentuk tunas pada bagian terminalnya.
Aktivitas giberelin meningkat disebabkan adanya pengaruh iklim mikro dimana suhu dan intensitas cahaya meningkat (Tsegaw, 2006), terutama di dataran medium, oleh karena itu pengurangan jumlah giberelin di dalam tanaman kentang dapat membantu dalam proses pembentukan ubi. Pengurangan giberelin tersebut dapat dilakukan dengan pemberian zat penghambat pertumbuhan (retardan) diantaranya paklobutrazol.

Penelitian Masniawati (2010) menyatakan dengan adanya retardan diharapkan adanya penghambatan yang akan mempercepat masuknya tanaman ke fase generatif karena energi untuk melakukan proses pertumbuhan cabang, buku, dan akar diakumulasikan untuk pembentukan ubi sehingga waktu yang dibutuhkan untuk membentuk ubi juga relatif lebih cepat. Peng-gunaan retardan juga mampu mempercepat tuberisasi, seperti yang dilakukan Stallknecht dan Farnsworth (1979) dikutip Zakaria dkk. (2007). Penambahan jumlah retardan dapat menurunkan aktivitas giberelin yaitu dengan menghentikan fase vegetatif (pemanjangan stolon) sehingga dapat memfokuskan aliran fotosintat untuk pembentukan dan pembesaran ubi (Sakya dkk., 2003).

Peningkatan jumlah sitokinin dan paklobutrazol di dalam tanaman dapat dilakukan dengan pemberian ZPT tersebut yang diaplikasikan pada daun tanaman kentang. Tujuan dari penelitian ini adalah untuk mempelajari pengaruh sitokinin dan paklobutrazol terhadap pertumbuhan benih kentang G2 hasil sistem NFT serta pengaruhnya terhadap kuantitas dan kualitas ubi kentang G3 di dataran medium desa Margawati kabupaten Garut.

\section{Bahan dan Metode}

Percobaan dilaksanakan di lahan percobaan di desa Margawati kabupaten Garut dengan ketinggian sekitar $700 \mathrm{~m}$ dpl. Penelitian dilakukan dari bulan Mei sampai September 2015.

Bahan-bahan yang dipergunakan dalam percobaan ini adalah benih kentang G2 hasil sistem NFT (dari percobaan sebelumnya), pupuk kandang, pupuk NPK, pestisida, sitokinin dan paklobutrazol sebagai Zat Pengatur Tumbuh. Alat-alat yang digunakan antara lain timbangan analitik, beaker glass, erlenmeyer, seperangkat alat budidaya tanaman (cangkul, kored, ember, embrat). Higrometer dan termometer, dan klorofilmeter. 
Metode penelitian yang digunakan adalah metoda eksperimental berupa Rancangan Acak Kelompok pola Faktorial yang terdiri dari 2 faktor dan 3 ulangan. Faktor pertama adalah : konsentrasi sitokinin yang terdiri atas empat taraf yaitu : $\mathrm{s} 1=0 \mathrm{ml} / \mathrm{l}, \mathrm{s} 2=5 \mathrm{ml} / \mathrm{l}, \mathrm{s} 3=10$ $\mathrm{ml} / 1$. s4 $=15 \mathrm{ml} / 1$. Faktor kedua adalah konsentrasi Paklobutrazol yang terdiri atas empat taraf yaitu : p1 $=0 \mathrm{ml} / \mathrm{l}, \mathrm{p} 2=15 \mathrm{ml} / \mathrm{l}$, p3 $=30 \mathrm{ml} / \mathrm{l}, \mathrm{p} 4=45 \mathrm{ml}$

Pengamatan dilakukan terhadap : Jumlah ubi per tanaman (knol), Bobot ubi per tanaman (g) , Bobot kering tanaman (g), Indeks Panen.

Tanah untuk media tanam diambil dari lapisan olah sedalam $20 \mathrm{~cm}$, kenudian disaring dan dimasukkan ke dalam polibag masingmasing berisi $12 \mathrm{~kg}$ tanah dan pupuk kandang dengan perbandingan 3:1.Polibag disusun sesuai dengan tata letak perlakuan dengan jarak masing masing polibag $50 \mathrm{~cm}$. Pemupukan diberikan sesuai dengan rekomendasi Balitsa lembang khususnya untuk kentang dataran medium jenis tanah Inceptisol yaitu : pupuk urea $(46 \% \mathrm{~N}) 300 \mathrm{~kg} / \mathrm{ha}$ yang diberikan dua kali yaitu pada saat tanam dan pada umur 30 hari setelah tanam, Pupuk SP-36 $\left(36 \% \mathrm{P}_{2} 0_{5}\right)$ sebanyak $250 \mathrm{~kg} /$ ha dan pupuk $\mathrm{KCl}\left(60 \% \mathrm{~K}_{2} \mathrm{O}\right)$ sebanyak $200 \mathrm{~kg}$ yang diberikan saat tanam (Setiawati dkk., 2007).

Penanaman dilakukan dengan meletakkan ubi secara mendatar dalam lubang tanam sedalam 5-7 cm, dengan tunas menghadap ke atas. Pupuk dibenamkan di sebelah kanan dan kiri tanaman kentang, kemudian di tutup dengan tanah. Untuk menghindari serangga dan hama tanah lainnya Karbofuran 3\% disebar di sekitar bibit dengan takaran 0,8 g per tanaman.

Sitokinin diberikan dua kali pada umur 10 hari dan 20 hari setelah tanam dengan konsentrasi sesuai perlakuan $(0,5,10$ dan 15 $\mathrm{ml} / \mathrm{L}$ ) untuk merangsang pertumbuhan bagian pupus (daun, batang). Setelah tanaman berumur 30 hari (pembentukan awal inisiasi stolon), diberikan perlakuan paklobutrazol dengan konsentrasi 0 , 15, 30, dan 45ml/L. Pemeliharaan tanaman terdiri dari penyiraman, penyiangan dan pengendalian hama dan penyakit.

Panen tanaman kentang dilakukan pada saat pertanaman kentang memiliki ciri daun telah menguning dan mengering, batang bawah berubah warna dari hijau menjadi kuning. Datadata yang diperoleh diuji dengan menggunakan Uji F dilanjutkan dengan Uji Jarak Berganda Duncan pada taraf nyata $5 \%$.

\section{Hasil dan Pembahasan}

Pengamatan Penunjang. Suhu rata-rata harian di desa Margasari kabupaten Garut 26,2 ${ }^{\circ} \mathrm{C}$. Suhu rata-rata tersebut kurang optimum untuk pertumbuhan tanaman kentang, sehingga pembentukan ubi tidak optimal. Keadaan iklim yang ideal untuk tanaman kentang adalah suhu rendah dengan suhu rata-rata harian $10-15{ }^{\circ} \mathrm{C}$ (Pitojo, 2004). Untuk dataran tinggi tropika, pembentukan ubi terjadi dengan baik jika suhu siang $25^{\circ} \mathrm{C}$, karena suhu siang hari yang terlalu tinggi akan menyebabkan tingginya respirasi dan transpirasi (Nonnecke, 1989).

Rata-rata kelembaban udara selama percobaan adalah sebesar di 76,4 \%. Kelembaban udara yang optimum untuk tanaman kentang berkisar $80-90 \%$ (Pitojo, 2004). Hal ini menunjukkan bahwa kelembaban udara selama percobaan kurang sesuai dengan kelembaban udara yang dikehendaki untuk pertumbuhan tanaman kentang.

\section{Pengamatan Utama}

Jumlah Ubi. Hasil analisis ragam ragam terhadap jumlah ubi menujukkan bahwa tidak terdapat pengaruh interaksi antara konsentrasi sitokinin dengan paklobutrazol terhadap jumlah ubi kentang. Secara mandiri, Sitokinin dan paklobutrazol berpengaruh terhadap jumlah ubi kentang (Tabel 1).

Tabel 1 menunjukkan bahwa sitokinin $5 \mathrm{ml} /$ L dapat meningkatkan jumlah ubi. Menurut Aryakian dan Hamidoghly (2010) sitokinin mempengaruhi pembelahan sel, induksi dan produksi dari kentang.Penggunaan sitokinin tergantung pada pengaruh hormon lainnya terutama giberelin, sitokinin berfungsi untuk meningkatkan pembentukan ubi tapi giberelin menghambat pertumbuhan ubi.

Paklobutrazol $15 \mathrm{ml} / \mathrm{L}$ dapat meningkatkan jumlah ubi (Tabel 1). Menurut Sakya, et al. (2013) penggunaan sitokinin saja tidak cukup, adanya penambahan retardan juga diperlukan untuk menghambat dan menekan aktivitas giberelin, agar penghambatan ini dapat mempercepat dan memfokuskan energi untuk pembentukan ubi.

Menurut Aryakia dan Hamidogli (2010) penggunaan sitokinin secara tunggal masih belum mampu meningkatkan produksi ubi kentang secara in vitro, penambahan retardan atau zat penghambat tumbuh sebagai inhibitor diharapkan dapat menghambat sintesis gibe- 
relin. Penggunaan paklobutrazol sebagai retardan yang dapat menghambat pemanjangan batang dan bekerja antara lain dengan menghambat sintesis giberelin.

Tabel 1. Pengaruh Mandiri Sitokinin dan Paklobutrazol terhadap Jumlah dan Bobot Ubi.

\begin{tabular}{|c|c|c|}
\hline Perlakuan & $\begin{array}{l}\text { Jumlah } \\
\text { Ubi (knol) }\end{array}$ & $\begin{array}{l}\text { Bobot Ubi } \\
\text { (g) }\end{array}$ \\
\hline s1 (0 ml L-1 sitokinin) & $10,50 \mathrm{a}$ & $134,82 \mathrm{a}$ \\
\hline $\mathrm{s} 2$ (5 ml L-1 sitokinin) & $11,42 \mathrm{~b}$ & $179,32 \mathrm{~b}$ \\
\hline s3 (10 ml L-1 sitokinin) & $10,25 \mathrm{a}$ & $122,09 \mathrm{a}$ \\
\hline s4 (15 ml L-1 sitokinin) & $10,75 \mathrm{a}$ & $137,81 \mathrm{a}$ \\
\hline $\begin{array}{l}\text { p1 }(0 \mathrm{ml} \mathrm{L}-1 \\
\text { paklobutrazol })\end{array}$ & $10,33 \mathrm{a}$ & $133,31 \mathrm{a}$ \\
\hline $\begin{array}{l}\text { p2 }\left(15 \mathrm{ml} \mathrm{L}^{-1}\right. \\
\text { paklobutrazol })\end{array}$ & $11,33 \mathrm{~b}$ & $160,87 \mathrm{~b}$ \\
\hline $\begin{array}{l}\text { p3 }\left(30 \mathrm{ml} \mathrm{L}^{-1}\right. \\
\text { paklobutrazol })\end{array}$ & 10,42 a & $168,88 \mathrm{~b}$ \\
\hline $\begin{array}{l}\text { p4 }\left(45 \mathrm{ml} \mathrm{L}^{-1}\right. \\
\text { paklobutrazol })\end{array}$ & $10,83 \mathrm{ab}$ & $110,98 \mathrm{ab}$ \\
\hline
\end{tabular}

Keterangan : Nilai rata-rata yang ditandai huruf yang sama menunjukkan tidak berbeda nyata menurut uji Duncan pada taraf 5\%.

Wattimena (1995) menyatakan bahwa kombinasi yang tepat pada pemberian ZPT mampu menghasilkan bobot ubi yang lebih besar. Menurut Frommer dan Sonnewald (1995) dikutip Tekalign (2006) persaingan antar inisiasi ubi akanmenurunkan jumlah ubi yang terbentuk, akan tetapi hal itu tidak akan terjadi tergantung pada waktu pemberian paklobutrazol dan kondisi tempat penanaman

Bobot Ubi. Bobot ubi kentang tidak dipengaruhi oleh interaksi antara sitokinin dan paklobutrazol (Tabel 1). Secara mandiri sitokinin berpengaruh terhadap bobot ubi kentang. Konsentrasi sitokinin $5 \mathrm{ml} / \mathrm{L}$ menghasilkan bobot ubi tertinggi.

Sitokinin diproduksi oleh akar dan dapat merangsang pembentukan akar lateral meskipun pada konsentrasi sama dapat menghambat pertumbuhan sumbu utama. Meskipun menghambat pemanjangan akar primer, sitokinin sangat meningkatkan diameternya yang disebabkan rangsangan bersama dengan auksin dari kegiatan kambium akar. Sitokinin berfungsi memacu pembelahan sel dan pembentukan organ, menunda penuaan, meningkatkan aktivitas wadah penampung hara, memacu perkembangan kuncup samping tumbuhan dikotil, dan memacu perkembangan kloroplas dan sintesis klorofil (Salisbury dan Ross, 1995).
Pemberian 15 dan $30 \mathrm{ml} / \mathrm{L}$ paklobutrazol dapat meningkatkan bobot ubi. Pemberian ZPT bergantung terhadap berbagai faktor seperti bagian tumbuhan, fase perkembangan, konsentrasi ZPT yang diberikan dan berbagai faktor lingkungan. Sakya et al. (2003) mengemukakan bahwa kebutuhan zat pengatur tumbuh yang diperlukan oleh suatu jenis tanaman sangat tergantung pada zat pengatur tumbuh dalam jaringan tanaman (endogenous), lingkungan tumbuh dan tingkat perkembangan jaringan, bagian yang diisolasi dan sebagainya.Wattimena (1995) mengatakan kombinasi yang tepat pada pemberian ZPT mampu menghasilkan bobot ubi yang lebih besar.

Bobot Kering Tanaman. Bobot kering tanaman kentang tidak dipengaruhi oleh interaksi sitokinin dan paklobutrazol, tetapi secara mandiri sitokinin dan paklobutrazol berpengaruh terhadap bobot kering tanaman. Bobot kering tanaman tertinggi dihasilkan oleh perlakuan sitokinin $5 \mathrm{ml} / \mathrm{L}$ (Tabel 2).

Tabel 2. Pengaruh Mandiri Sitokinin dan Paklobutrazol terhadap Bobot Kering Tanaman Kentang

\begin{tabular}{lcc}
\hline \hline Perlakuan & $\begin{array}{c}\text { Bobot } \\
\text { kering } \\
\text { tanaman }\end{array}$ & $\begin{array}{c}\text { Indeks } \\
\text { Panen }\end{array}$ \\
\hline s1 (0 ml L-1 sitokinin) & $190,34 \mathrm{~b}$ & $3,75 \mathrm{a}$ \\
s2 (5 ml L-1 sitokinin) & $238,46 \mathrm{c}$ & $4,37 \mathrm{~b}$ \\
s3 (10 ml L-1 sitokinin) & $158,48 \mathrm{a}$ & $4,16 \mathrm{~b}$ \\
s4 (15 ml L-1 sitokinin) & $190,86 \mathrm{~b}$ & $4,73 \mathrm{~b}$ \\
\hline p1 (0 ml L-1 & $177,83 \mathrm{a}$ & $3,91 \mathrm{a}$ \\
paklobutrazol) & & \\
p2 (15 ml L-1 & $227,63 \mathrm{~b}$ & $3,52 \mathrm{a}$ \\
paklobutrazol) & & \\
p3 (30 ml L-1 & $221,31 \mathrm{~b}$ & $4,42 \mathrm{a}$ \\
paklobutrazol) & & \\
p4 (45 ml L-1 & $151,38 \mathrm{a}$ & $4,15 \mathrm{a}$ \\
paklobutrazol) & & \\
\hline \hline
\end{tabular}

Keterangan : Nilai rata-rata yang ditandai huruf yang sama menunjukkan tidak berbeda nyata menurut uji Duncan pada taraf 5\%.

Aryakian dan Hamidoghly (2010) menyatakan bahwa sitokinin mempengaruhi pembelahan sel, induksi dan produksi dari dari kentang. Tabel 2 menunjukkan paklobutrazol mempengaruhi bobot kering tanaman, perlakuan 15 dan $30 \mathrm{ml} / \mathrm{L}$ paklobutrazol mampu meningkatkan bobot kering tanaman. Paklobutrazol menghambat pembentukan giberelin, dimana giberellin dapat menghambat pembentukan ubi, 
menurunkan kekuatan sink ubi dan mendorong pertumbuhan stolon dan batang. Hal ini menunjukkan pemberian paklobutrazol sangat dibutuhkan untuk mengatasi dampak yang timbul akibat keberadaan giberelin yang terus berproduksi akibat suhu yang tinggi di dataran medium.

Harjadi (1993) dikutip Sakya (2003) menjelaskan ketika proses generatif lebih dominan, karbohidrat pada tanaman kentang lebih banyak disimpan dari pada dipakai karena hal ini mendukung pembengkakan stolon. Sakya (2003) melanjutkan bahwa sitokinin BAP yang digunakan dalam penelitian ini bisa menyebabkan rangsangan pembelahan sel sehingga menghasilkan ruangan yang dapat digunakan sebagai tempat untuk akumulasi zat tepung, yang nantinya oleh sitokinin akan merangsang pengubian dengan mengatur aktivitas enzim yang mensintesa tepung terutama enzim phosphorylase dan sintesa tepung (MingoCastle et al. 1976 dikutipSakya 2003).

Paklobutrazol berpengaruh terhadap bobot kering tanaman. Senyawa paklobutrazol dapat menghambat aktivitas dan biosintesis giberelin sehingga proses pemanjangan sel terhambat yang akhirnya mempersingkat pertumbuhan vegetatif dan secara tidak langsung fotosintat dialihkan ke pertumbuhan reproduktif (Wilkinson dan Richard, 1991).

Indeks Panen. Indekspanen ubi kentang tidak dipengaruhi oleh interaksi sitokinin dengan paklobutrazol, tetapi dipengarhi secara mandiri oleh sitokinin dan paklobutrazol. Pemberian sitokinin dapat meningkatkan indeks panen ubi, tetapi peningkatan konsentrasi dari 5 menjadi 15 tidak meningkatkan indeks panen, indeks panen terendah dihasilkan oleh perlakuan tanpa sitokinin (Tabel 2). Hal ini sejalan dengan bobot ubi yang dihasilkan seperti terlihat pada Tabel 1. Indeks Panen menunjukkan perbandingan ubi dengan brangkasan

Pemberian sitokinin dapat meningkatkan indeks panen ubi, hal ini menunjukkan bahwa sitokinin dapat meningkatkan pembentukan dan pengisian ubi. Peningkatan konsentrasi sitokinin sampai $15 \mathrm{ml} / \mathrm{L}$ ternyata tidak meningkatkan indeks panen, hal ini diduga konsentrasi auksin sudah terlalu tinggi. Sakya et al. (2003) mengemukakan bahwa kebutuhan zat pengatur tumbuh yang diperlukan oleh suatu jenis tanaman sangat tergantung pada zat pengatur tumbuh dalam jaringan tanaman (endogenous), lingkungan tumbuh dan tingkat perkembangan jaringan, bagian yang diisolasi dan sebagainya.

Sitokinin secara garis besar dapat memacu pertumbuhan vegetatif bagian atas tanaman kentang, sedangkan pemberian paklobutrazol dapat mempercepat masa inisiasi ubi, sehingga pada awal pertanaman sitokinin dapat memacu pertumbuhan vegetatif bagian atas, lalu setelah pertumbuhan optimal dihentikan oleh paklobutrazol untuk merangsang pembentukan dan inisiasi ubi. Aplikasi sitokinin dan paklobutrazol diharapkan dapat menghasilkan benih kentang $\mathrm{G}_{2}$ dengan kuantitas dan kualitas yang baik.

Paklobutrazol tidak mempengaruhi indeks panen. Keberadaan hormon giberelin pada apeks pucuk yang tinggi akan menurunkan nilai indeks panen. Pertumbuhan vegetatif bagian atas tanaman akan terangsang lebih cepat dibandingkan bagian ubi. Faktor suhu juga dapat meningkatkan kandungan giberelin pada ujung stolon. Terhambatnya tuberisasi dan terjadinya pemanjangan stolon akibat aktivitas dan konsentrasi giberelin yang meningkat di ujung stolon akan menurunkan indeks panen.

Mariana (2010) menyatakan bahwa terdapat dua faktor lingkungan yang mempengaruhi proses pembentukan ubi antara lain lama penyinaran dan suhu. Ewing (1981) menyatakan bahwa tekanan suhu tinggi dapat menurunkan hasil ubi kentang melalui dua hal, rendahnya laju fotosintesis dalam penyediaan asimilat untuk seluruh pertumbuhan tanaman dan mengurangi distribusi karbohidrat ke ubi sehingga hasilnya lebih rendah.

\section{Kesimpulan}

Dari hasil percobaan dapat ditarik kesimpulan bahwa :

1. Konsentrasi sitokinin tidak berinteraksi dengan konsentrasi paklobutrazol dalam mempengaruhi kuantitas dan kualitas benih G3 kentang yang dihasilkan yang berasal dari kentang G2 hasil Nutrient Film Technique.

2. Konsentrasi sitokinin yang paling baik dalam menghasilkan kuantitas dan kualitas kentang adalah $5 \mathrm{ml} / \mathrm{L}$. Konsentrasi paklobutazol yang paling baik dalam menghasilkan kuantitas dan kualitas kentang adalah $15 \mathrm{ml} / \mathrm{L}$. 


\section{Daftar Pustaka}

Aryakia, E. and Y. Hamidogli. 2010. Comparison of Kinetin and 6-Benzyl Amino Purine Effect on In vitro Microtuberization of Two Cultivars of Potato (Solanum tuberosum L.). American-Eurasian J. Agric. \& Environ. Sci, 8(6):710-714.http://www.idosi.org/aejaes/ jaes8(6)/15.pdf (diakses pada 20 Des. 2013).

Badan Pusat Statistik. 2014. Produksi dan Produktivitas Kentang, 2012. Diakses dari bps.go.id. (diakses pada 10 Januari 2015)

Bradshaw, E. Jhon and G. Ramsay. 2009. Potato Origin and Production. Elsevier Inc., USA.

FAOSTAT. 2006. FAOSTAT Agriculture. Diakses dari www.faostat.fao.org (diakses pada tanggal 2 Agustus 2012).

Mariana. 2010. Pertumbuhan dan Hasil Empat Kultivar Kentang (Solanum tuberosum L.) Di Dataran Medium Dengan Aplikasi Paclobutrazol dan Kerapatan Naungan. Tesis.

Masniawati, A., 2010. Pemanfaatan Filtrat Cendawan Lasiodiplodia theobromae Sebagai Penginduksi Pembentukan Umbi Mikro Kentang Solanun tuberosum Linn. Varietas Granola Secara in vitro. Diakses dari http://www.pdf-archive.com/2011/

03/16/42-a-masniawati/42-a-asniawati.pdf (diakses pada 2 Agustus 2012)

Nonnecke, L.I. 1989. Vegetable production. Van Norstrand. Reinhold.Canada p. 175-200.

Pitojo, S. 2004. Benih Kentang. Kanisius. Yogyakarta.

Sakya, A.T., A. Yunus, Samanhudi dan U. Baroroh. 2003. Pengaruh Coumarin dan Aspirin dalam Menginduksi Umbi Mikro
Kentang (Solanum tuberosum L.). Agrosains Volume 5 No 1.

Salisbury, F.B dan C.W. Ross. 1995. Fisiologi Tumbuhan. Terjemahan oleh Diah R. Lukman dan Sumaryono. ITB. Bandung

Setiawati, N., R. Murtiningsih, G.A. Sopha dan T. Handayani. 2007. Petunjuk Teknis Budidaya Sayuran. Balai Penelitian Tanaman Sayuran, Bandung.

Tekalign, T. 2006. Response of potato to Paclobturazol and Manipulation of Reproductive Growth Under Tropical Condistions. A paper presented to combined Congress 2005, Department of Plant Production and Soil Science, in The Faculty of Natural and Agricultural Sciences, University Pretoria.

Wattimena, G. A. 1995. In Vitro Microtubers As An Alternative technology for Potato Production. Dept of Agronomy, Fac. of Agriculture Bogor Agric. University (IPB), Bogor Indonesia Dept of Horticulture Univ. of Wisconsin, Madison, USA 1995.

Wattimena. G. A. 2000. Pengembangan Propagul Kentang Bermutu dan Kultivar Kentang Unggul dalam Mendukung Peningkatan Hasil Kentang di Indonesia. Orasi Ilmiah Guru Besar Tetap Hortikulutra. Fakultas Pertanian. IPB. Bogor.

Wilkinson, R. I.And D. Richard. 1991. Influence of paclobutrazol on growth and flowering of the rhododendron 'sirrobrtpeel'. Hort 26(3) : 282-284.

Zakaria, M. M.M. Hossain, M.A. K. Mian, T. Hossain and N. Sultana. 2007. Effect of Nitrogen and Potassium on In vitro Tuberization of Potato. Plant Tissue Cult.\& Biotech. 17(1): 79-85, 2007 (June) 